\title{
O PROCESSO DE ADAPTAÇÃO DE INTELIGÊNCIAS CONSTRUTIVAS ATRAVÉS DO TEMPO
}

\author{
LUÍSA AMANDA DE MACÊDO LIMA | UFRN \\ RUBENILSON BRAZÃO TEIXEIRA, Dr. | UFRN
}

\section{INTRODUÇÃO}

O saber-fazer construtivo têm passado por mudanças ao longo dos séculos, promovidas, sobretudo, pelos avanços tecnológicos. Diante da tecnologia formal de construção, conhecimentos vernaculares oriundos de Culturas Construtivas Tradicionais (MORLEY, 1987), tendem ao desaparecimento ou sofrem processos de adaptação a essas mudanças, especialmente no tempo presente. Porém, quais vestígios dessas antigas tradições no ato de construir podemos encontrar ao longo desses processos de adaptação?

Algumas obras que se adequam à atualidade, por exemplo, são capazes de expressar_um senso regionalista por meio de aspectos vernaculares, anti-gos saberes construtivos passados de geração à geração, ou seja, Inteligências Construtivas. (FERREIRA, 2012)

Geralmente, tais obras são apenas vestígios do que seria uma concepção de arquitetura vernacular em sua integralidade, mesmo assim, possuem aspectos ou indícios de antigas tradições construtivas, como é o caso de alguns projetos de Diébédo Francis Kéré, na África e algumas obras de Severiano Porto no Brasil.

A fim de averiguar e compreender a expressão de tais arquiteturas "híbridas" (dotadas de alguns aspectos vernaculares e ao mesmo tempo de um certo nível de tecnologia formal), esta pesquisa de dissertação de mestrado, atualmente em desenvolvimento no Programa de Pós Graduação em Arquitetura e Urbanismo (PPGAU) da Universidade Federal do Rio Grande do Norte (UFRN), pretende investigar como as tradições no ato de construir, presentes na arquitetura vernacular, são apropriadas por obras arquitetônicas e se expressam na contemporaneidade.

\section{OBJETIVO}

O principal objetivo desta pesquisa, é investigar o processo de adaptação de Inteligências Construtivas de origens vernaculares à contemporaneidade.

\section{METODOLOGIA}

A metodologia desta pesquisa consiste em análises de obras contemporâneas com o caráter híbrido citado, por meio de dois eixos temáticos: Culturas Construtivas Tradicionais e Inteligências Construtivas, através de levantamentos bibliográficos e docu-mentais, estudos de casos indiretos e formais, entre outros. Em sua etapa inicial, é demarcado um estudo bibliográfico dos autores que tratam destes eixos, por meio de uma apreciação reflexiva de suas pesquisas e publicações. Ao longo de seu desenvolvimento, são colocados em foco os aspectos tradicionais vernaculares dos edifícios que assumem esse caráter híbrido, ressaltando suas adaptações contemporâneas e, buscando, enfim, uma compreensão mais profunda e consistente sobre o processo de apropriação e adaptação de Inteligências Construtivas vernaculares à atualidade.

\section{EIXOS DE PESQUISA}

As Culturas Construtivas fazem parte de um sistema caracterizado pelo acumulo de experiências e de valores por meio de sistematizações, normas e divisões de trabalhos relacionados a ação construtiva. Frente a esta perspectiva, será adotado o termo Cultura Construtiva tal como compreendido nas definições de Jane Morley (1987) e de Howard Davis (2006), sendo aquela que marca o modo único com o qual grupos sociais constroem.

Ela pode ser entendida em duas escalas (figura 1), uma escala mais ampla relativa a produção em massa de casas, igrejas, escolas, cidades, nações, ou seja, do mundo como o conhecemos hoje (DAVIS, 2006), ou em uma escala menor e mais focada, geralmente chamada de Cultura Construtiva Tradicional, que consiste nas tradições e valores no ato de construir de povos ou grupos sociais (MORLEY, 1987).

O termo Inteligência Construtiva, por outro lado, é mais utilizado na filosofia e na antropologia sem grandes conotações, e suas aplicações são variadas. Sob uma ótica arquitetônica, no entanto, ele pode ser compreendido como o "saber-fazer construtivo" presente em Culturas Construtivas 
Tradicionais. Estes saberes, quando apropriados por uma lógica projetual, se traduzem em obras arquitetônicas contemporâneas que apresentam, em alguns casos, indícios de antigas tradições ou técnicas construtivas.

Por fim, através da investigação destas Inteligências Construtivas de origens vernaculares em obras de caráter híbrido, esta pesquisa pretende ressaltar a importância de compreender os processos de produção da arquitetura vernacular na atualidade, contribuindo de forma acadêmica e social em futuras pesquisas sobre o tema.

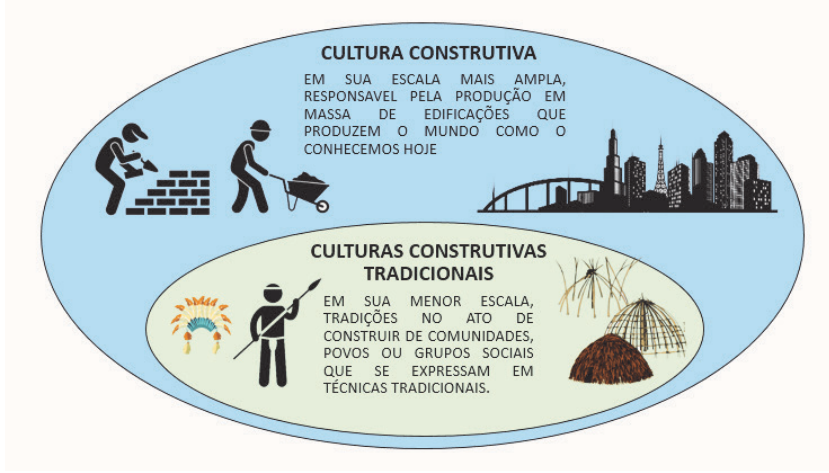

Figura 1 - Esquema que representa as diferentes escalas da Cultura Construtiva Fonte: Desenvolvido pela autora, 2019.

\section{REFERÊNCIAS}

DAVIS, Howard. The culture of building. New York: Oxford University Press, 2006.

FERREIRA, Thiago Lopes. Um olhar sobre os processos de produção das culturas construtivas tradicionais, Risco. - Revista de Pesquisa em Arquitetura e Urbanismo, São Paulo: IAU - USP, 2012.

MORLEY, Jane. Building Themes in Construction History: recent work by the Delaware Valley Group, Construction History, Vol. 3, 1987. 